\title{
Energy Drink Consumption and its Effects on Student Pilots: Perceptions of Collegiate Flight Students
}

\author{
Timm J. Bliss and Chad L. Depperschmidt \\ Oklahoma State University
}

\begin{abstract}
During the past ten years, there have only been a few published research studies examining the possible behavioral consequences of energy drink consumption by college students. With that in mind, the authors surveyed collegiate aviation flight students regarding their consumption of energy drinks and their perceptions of side effects and behavioral patterns after consuming energy drinks. Results show that $57 \%$ of student pilots surveyed consume energy drinks 1-3 times a week. In addition, 56\% stated they can only consume one energy drink (16 ounces) without experiencing side effects. A majority (60\%) reported they consumed energy drinks the same day they piloted an aircraft; and the same percentage (60\%) had observed other student pilots consuming energy drinks the same day they piloted an aircraft. And yet, $67 \%$ of the participating flight students agree that energy drinks have an effect on collegiate flight students' ability to pilot an aircraft.
\end{abstract}

\section{INTRODUCTION}

Inspired by the success of the Red Bull energy drink, which entered the United States market in 1997; more than 1,000 smaller players have also entered the energy drink market (Helm, 2005). As a result, energy drinks have become the fastest selling category in the beverage industry. Since 2001, the market for energy drinks in the United States has increased exponentially. From 2002 to 2005, the consumption of energy drinks increased by $50 \%$ each year; in 2006, over 500 new energy drinks were introduced worldwide and total sales equaled $\$ 3.2$ billion. Sales of energy drink products such as Red Bull, Full Throttle, Nos, and Monster are expected to reach \$9 billion in the United States in 2011 (Park, 2011).

A large part of this yearly increase in energy drink consumption is a result of the addictive properties of energy drinks and aggressive advertising campaigns by manufacturers directed toward the college student (Buchanan, 2010). The objective of this marketing strategy is straight-forward; provide college students, who have a harder time resisting immediate gratification, with free samples to get them using the energy drink product. Then, once they are hooked, take full advantage of the stimulating and addictive properties of these drinks (Pohler, 2010).

Energy drinks have no doubt taken off on college campuses, but with newly introduced energy drink products comes the question of whether or not the drinks will have a more lasting effect than a quick energy buzz. What college students may be unaware of is that newer brands of energy drinks such as Spike and Redline, contain up to 4 times the amount of caffeine per ounce, and also contain powerful herbal compounds such as yohimbine hydrochloride (HCL) and evodamine which are far more dangerous stimulants than caffeine (Energyfiend.com, 2010).

In October 2010, Ramapo College forbade their students from consuming energy drinks - the beverage of choice for these students. The energy drink ban comes after the college reported that 23 students were hospitalized for alcohol intoxication at the beginning of the fall 2010 semester. One of the energy drinks banned by Ramapo was Four Loco, an energy drink containing $12 \%$ alcohol; the alcohol equivalent of consuming four cans of beer. The manufacturer behind the $\$ 3$ drink describes Four Loco as a premium caffeinated alcoholic beverage which is available in nine fruity carbonated flavor including cranberry lemonade, lemon lime, and blue raspberry (Keegan, 2010). By the end of November, 2010, 
several states across the nation had banned the sale of Four Loko following this and many other incidents of drunkenness, illness and hospitalizations on college campuses (Melnick, 2010).

Recent research has indicated that young adults (those under age 25) are more vulnerable to substance use (Miller \& Carroll, 2006). This is an important consideration for college students because the earlier they start consuming energy drinks, the greater the likelihood of future psychological problems including addiction, depression and anxiety.

Energy drink use has become widespread among college students and evidence suggests that usage rates could be even higher among special student populations (collegiate flight students) who are under increased cognitive and performance demands (Oteri et al., 2007). However, only a small number of research studies have been conducted to determine energy drink usage among college students. A 2007 study researched approximately 500 United States college students and found that 51\% reported drinking at least one energy drink each month during the semester. The reasons for consuming energy drinks were: low energy levels, insufficient sleep, studying, performing a function for an extended period of time, and mixing with alcohol. In addition, the students reported several side effects from consuming energy drinks: headaches, heart palpitations, and jolt and crash episodes (Malinauskas et al., 2007).

In another study conducted in 2008, the researcher examined the relationships between energy drink consumption and risk-taking in 795 undergraduate students. According to the study's findings, frequent energy drink consumers (six or more days a month) were three more times likely than less-frequent energy drink consumers or non-consumers to have smoked cigarettes, abused prescription drugs and been involved in a violent altercation. Energy drink users were also more likely to engage in other forms of risk-taking: unsafe sex, not wearing a seatbelt, participating in extreme sports and doing something dangerous on a dare (University of Buffalo, 2008).

At the time of this study, however; only one identified study (Depperschmidt, Bliss \& Woolsey, 2010) researched the effects of energy drinks on collegiate student pilots. The researchers studied the overall effects of energy drink consumption on pilot skills in collegiate flight students in three distinct areas; straight and level flight, complex turns, and in-flight emergencies. This study concluded the following:

- When comparing student pilots' straight and level flight segments, 87\% of the pilots had a larger number of point deductions after consuming one energy drink when compared to the pilots consuming a placebo drink.

- When measuring the total amount of time to complete the complex turns, 53\% of the student pilots completed the maneuver quicker after consuming an energy drink; however, it took the energy drink participants approximately ten additional seconds to recover from the complex turn and achieve straight and level flight when compared to the placebo participants.

- When measuring the ability of the student pilots to accurately follow a five-step in-flight emergency checklist, participants were less accurate after consuming an energy drink compared to the placebo. Furthermore, it took the energy drink participants an average of 52 seconds to complete the emergency checklist; whereas the placebo participants were able to complete the checklist in lesser time, an average of 47 seconds.

Having obtained these specific research results showing that college flight students became less able to perform routine flight maneuvers or apply what they have learned to unpredicted flight situations after consuming one energy drink, the authors decided to investigate these same flight students' perceptions 
regarding the effects of energy drink consumption. In addition, the authors were interested in examining the students’ demographic information regarding their own energy drink consumption.

\section{RESEARCH METHODOLOGY}

The research instrument developed by the authors was administered at Oklahoma State University, a four-year research institution that offers a comprehensive aviation curriculum; awarding bachelor degrees in several aviation disciplines including professional pilot. Exploratory in nature, this study was designed to elicit student information and perceptions related to energy drink consumption and the resulting effects on collegiate flight students.

This research was guided by the following research questions:

1. Do collegiate flight students typically consume energy drinks? If so, do they consume energy drinks the same day they pilot an aircraft?

2. Do collegiate flight students believe energy drinks have an effect on their ability to pilot an aircraft?

3. Do collegiate flight students believe the consumption of energy drinks can be associated with behavioral problems (academic misconduct, violence, risky or dangerous activities)?

\section{Selection of the Research Population}

The population for this study was 30 undergraduate aviation students majoring in Professional Pilot at Oklahoma State University and currently enrolled in a flight course for academic credit. These are the same flight students that participated in the 2010 study focusing on the effect of energy drink consumption on collegiate flight students' pilot skills in simulated flight (Depperschmidt, Bliss \& Woolsey, 2010). Permission to perform this research study involving collegiate flight students was approved by the Institutional Review Board at Oklahoma State University (IRB application number: ED1017).

\section{Description of Research Instrument}

The research instrument for this study was developed to identify demographic information related to collegiate flight students and investigate their perceptions related to energy drink consumption. The instrument consisted of three parts: demographic information, Likert-scale statements, and personal comment section. The first part requested demographic information specific to each collegiate flight student participating in the study. The second part of the research instrument listed Likert-scale statements with ordinal measurement pattern options ranging from: (1) Strongly Agree, (2) Agree, (3) Disagree, and (4) Strongly Disagree. These statements were intended to gain insight into the perceptions of the participating flight student related to energy drink consumption and the effects of these drinks on student pilots. The final part of the instrument consisted of a text box offering the participants an opportunity to provide additional comments they believed would be beneficial to the study.

\section{Validity and Reliability of Research Instrument}

Concurrent validity has to do with the correlation between instrument measurement items (Likertscale) and observed and accepted standard measures. Basically, the authors are determining if proposed measures for a given concept exhibit the same magnitude of correlation with other variables. In a recent study, the authors demonstrated that college flight students became less able to perform routine flight 
maneuvers or apply what they have learned to unpredicted flight situations after the consumption of one energy drink; providing the argument that the side effects of energy drink consumption reduce performance levels of alertness issues and concentration levels (Depperschmidt, Bliss \& Woolsey, 2010). The authors now wish to test this relationship measure further by having these same flight students complete a research instrument; thereby identifying their perceptions of energy drink consumption and side effects after consumption. By comparing the research results of their previous study with the ten Likert-scale statements from this study, the authors will establish concurrent validity with the Likert-scale section of the research instrument.

Face validity is the validity of a test at face value. In other words, a test can be said to have face validity if it "looks like" it is going to measure what it is supposed to measure. To determine face validity, the Likert-scale statements included in the research instrument were examined by five collegiate aviation professionals. After review of the statements, all of the aviation professionals agreed that it looks like a good test to measure student perceptions of energy drink consumption; thereby establishing the face validity of the test.

Furthermore, the Likert-scale statements listed in the research instrument were analyzed for internal reliability by using Cronbach's alpha. Cronbach's alpha is a general formula for estimating internal consistency based on a determination of how all items on a test to all other items and to the total test (Gay, Mills, \& Airasian, 2006). George and Mallery (2003) have established the following Cronbach's alpha acceptance scale: “ - > .9 - Excellent, - > .8 - Good, - > .7 - Acceptable, - > .6 - Questionable, - > .5 - Poor, and - <.5 - Unacceptable” (p. 231). For this study, the authors entered all data into a Microsoft Excel spreadsheet and exported it into SPSS version 17.0 for analysis. Cronbach's alpha analysis resulted in a coefficient alpha reliability score of .717, an acceptable level of internal reliability.

\section{RESULTS}

Each participating collegiate flight student was asked to identify their academic classification. Table 1 indicates that of the 30 respondents; $7 \%$ were freshman, $17 \%$ were sophomores, $43 \%$ were juniors, and $33 \%$ were seniors. The gender of the flight students was also solicited in this study. Eighty-three percent of the flight students were male and $17 \%$ were female students.

Table 1. Academic Classification of Collegiate Flight Students

\begin{tabular}{l|l|l}
$\begin{array}{l}\text { Academic } \\
\text { Classification }\end{array}$ & Respondents & $\begin{array}{l}\text { Percentage of } \\
\text { Respondents }\end{array}$ \\
\hline \hline Freshman & 2 & $7 \%$ \\
Sophomore & 5 & $17 \%$ \\
Junior & 13 & $43 \%$ \\
Senior & 10 & $33 \%$
\end{tabular}

In Table 2, flight hours amassed by each responding collegiate flight student were separated into six sub groups: 25-49; 50-99; 100-149; 150-199; 200-249; and 250 and over. Approximately half (53\%) of the participants had accumulated 25-149 flight hours; whereas, the other half of total respondents (47\%) indicated they had over 150 flight hours. 
Table 2. Total Flight Hours of Collegiate Flight Students

\begin{tabular}{l|l|l} 
Total Flight Hours & Respondents & $\begin{array}{l}\text { Percentage of } \\
\text { Respondents }\end{array}$ \\
\hline \hline $25-49$ & 2 & \\
$50-99$ & 7 & $7 \%$ \\
$100-149$ & 7 & $23 \%$ \\
$150-199$ & 5 & $23 \%$ \\
$200-249$ & 1 & $17 \%$ \\
250 \& over & 8 & $3 \%$ \\
\hline
\end{tabular}

Table 3 indicates how often each collegiate flight student typically consumes energy drinks. The majority of respondents (57\%) indicated they consume an energy drink 1-3 times a week. Forty percent of these flight students stated they typically do not consume energy drinks.

Table 3. Consumption of Energy Drinks

\begin{tabular}{l|l|l}
$\begin{array}{l}\text { Energy Drink } \\
\text { Consumption }\end{array}$ & Respondents & $\begin{array}{l}\text { Percentage of } \\
\text { Respondents }\end{array}$ \\
\hline \hline & & \\
0 per week & 12 & $40 \%$ \\
1-3 per week & 17 & $57 \%$ \\
4-6 per week & 1 & $3 \%$ \\
7-9 per week & 0 & $0 \%$ \\
10 or more per week & 0 & $0 \%$
\end{tabular}

Of the 18 students (60\%) who typically consume energy drinks (Table 3), they were asked to respond to a question indicating how many 16-ounce energy drinks they can consume daily without experiencing side effects (jolt and crash episodes, headaches, heart palpitations, etc.). These students' responses are presented in Table 4. The majority of the students (56\%) responded they only have to consume one energy drink to experience side effects. A 2007 study at Wayne State University found that blood pressure and heart rates did in fact increase in healthy adults who drank two cans of energy drink in a given day (American Heart Association, 2007).

Table 4. Consumption of Energy Drinks without Experiencing Side Effects

\begin{tabular}{l|l|l}
$\begin{array}{l}\text { Energy Drink } \\
\text { Consumption }\end{array}$ & Respondents & $\begin{array}{l}\text { Percentage of } \\
\text { Respondents }\end{array}$ \\
\hline \hline & 10 & \\
2 & 7 & $56 \%$ \\
3 & 1 & $39 \%$ \\
4 & 0 & $5 \%$ \\
More than 4 & 0 & $0 \%$ \\
& & $0 \%$
\end{tabular}


The reasons collegiate flight students consume energy drinks are presented in Table 5. A higher number of responses, 75, were received from the flight students because the survey question asked the students to "check all that apply" regarding the reasons they consume energy drinks. The three most common reasons the students consumed energy drinks were: needing more energy (23\%), driving an automobile for a long period of time (20\%), and studying for an exam/completing homework (17\%). Those who chose the option of other had the opportunity to identify their reasons for consuming energy drinks; three students indicated they liked the taste, two indicated they consumed energy drinks while at work, and one student responded they do not consume energy drinks.

Table 5. Reasons to Consume Energy Drinks

\begin{tabular}{l|l|l}
$\begin{array}{l}\text { Reasons for Energy } \\
\text { Drink Consumption }\end{array}$ & Responses & $\begin{array}{l}\text { Percentage of } \\
\text { Responses }\end{array}$ \\
\hline \hline Need More Energy (in general) & 17 & $23 \%$ \\
Driving Automobile (extended period) & 15 & $20 \%$ \\
Study for Exam/Complete Homework & 14 & $17 \%$ \\
Sleep Deprivation & 11 & $15 \%$ \\
Mix with Alcohol (partying) & 8 & $11 \%$ \\
Other & 8 & $11 \%$ \\
Piloting Aircraft (extended period) & 2 & $3 \%$ \\
Peer/Societal Pressure & 0 & $0 \%$
\end{tabular}

As indicated in Table 6, the majority (60\%) of surveyed collegiate flight students indicated they have consumed an energy drink the same day they piloted an aircraft. Since 18 of the 30 participating students (60\%) indicated they consumed at least one energy drink on a weekly basis (Table 3), these same 18 students are responsible for consuming an energy drink on the same day they piloted an aircraft. Furthermore, $60 \%$ of the students indicated they have seen other student pilots consuming energy drinks the same day these students have piloted an aircraft.

Table 6. Consumption of Energy Drink Same Day Piloted an Aircraft

\begin{tabular}{l|l|l}
$\begin{array}{l}\text { Energy Drink } \\
\text { Consumption }\end{array}$ & Respondents & $\begin{array}{l}\text { Percentage of } \\
\text { Respondents }\end{array}$ \\
\hline \hline & 18 & $60 \%$ \\
Yes & 12 & $40 \%$ \\
No &
\end{tabular}

Likert-scale statements that examine the collegiate flight student's perceptions regarding energy drinks and energy drink effects are presented in Table 7. Seventy percent of the respondents agreed, 
compared with 30 percent that disagreed with the statement: Consumption of energy drinks is considered similar to consumption of coffee. Over half of respondents (57\%) agreed with the statement: Jolt and crash (no/low energy) episodes are typical after consumption of energy drinks. The remaining $43 \%$ disagreed with the statement. One flight student wrote on their survey, "Although consumption of energy drinks does give me some energy, I find the biggest concerns comes 2-4 hours after consumption. Although I will be fatigued after the 'crash’ I will still be unable to sleep.”

Approximately two-thirds of the flight students (63\%) indicated they agreed; opposed to 37\% that disagreed with the statement: Heart palpitations (pounding or racing) are common after consuming energy drinks. However, only about one-fourth of the students (27\%) agreed that headaches are common after consuming energy drinks.

Even though 53\% of collegiate flight students disagreed with the statement: Chronic use of energy drinks can lead to other use of stimulants (Adderall, Ritalin, etc.), the remaining $47 \%$ of responding students agreed that chronic energy drink consumption can lead to other use of stimulants. But surprisingly, only $13 \%$ of student pilots agreed with the statement: The consumption of energy drinks can be associated with risky or behavior problems (academic misconduct, doing something dangerous on a dare, interpersonal violence, etc.).

Table 7. Collegiate Flight Students’ Perception of Energy Drinks Regarding Side Effects

\begin{tabular}{|c|c|c|c|c|}
\hline Likert-Scale Statements & SA & A & $\mathrm{D}$ & SD \\
\hline $\begin{array}{l}\text { Consumption of energy drinks is considered similar to } \\
\text { consumption of coffee. }\end{array}$ & $\begin{array}{l}3 \\
10 \%\end{array}$ & $\begin{array}{l}18 \\
60 \%\end{array}$ & $\begin{array}{l}8 \\
27 \%\end{array}$ & $\begin{array}{l}1 \\
3 \%\end{array}$ \\
\hline $\begin{array}{l}\text { Jolt and crash (no/low energy) episodes are typical after } \\
\text { consumption of energy drinks. }\end{array}$ & $\begin{array}{l}2 \\
7 \%\end{array}$ & $\begin{array}{l}15 \\
50 \%\end{array}$ & $\begin{array}{l}12 \\
40 \%\end{array}$ & $\begin{array}{l}1 \\
3 \%\end{array}$ \\
\hline Headaches are common after consuming energy drinks. & $\begin{array}{l}1 \\
3 \%\end{array}$ & $\begin{array}{l}7 \\
24 \%\end{array}$ & $\begin{array}{l}18 \\
60 \%\end{array}$ & $\begin{array}{l}4 \\
13 \%\end{array}$ \\
\hline $\begin{array}{l}\text { Heart palpitations (pounding or racing) are common after } \\
\text { consuming energy drinks. }\end{array}$ & $\begin{array}{l}1 \\
3 \%\end{array}$ & $\begin{array}{l}18 \\
60 \%\end{array}$ & $\begin{array}{l}11 \\
37 \%\end{array}$ & $\begin{array}{l}0 \\
0 \%\end{array}$ \\
\hline Energy drinks have no effect on short term memory. & $\begin{array}{l}1 \\
3 \%\end{array}$ & $\begin{array}{l}16 \\
54 \%\end{array}$ & $\begin{array}{l}13 \\
43 \%\end{array}$ & $\begin{array}{l}0 \\
0 \%\end{array}$ \\
\hline $\begin{array}{l}\text { Chronic use of energy drinks can lead to other use of } \\
\text { stimulants (Adderall, Ritalin, etc.). }\end{array}$ & $\begin{array}{l}2 \\
7 \%\end{array}$ & $\begin{array}{l}12 \\
40 \%\end{array}$ & $\begin{array}{l}12 \\
40 \%\end{array}$ & $\begin{array}{l}4 \\
13 \%\end{array}$ \\
\hline $\begin{array}{l}\text { The consumption of energy drinks can be associated with } \\
\text { risky or behavior problems (academic misconduct, doing } \\
\text { something dangerous on a dare, interpersonal violence, etc.). }\end{array}$ & $\begin{array}{l}1 \\
3 \%\end{array}$ & $\begin{array}{l}3 \\
10 \%\end{array}$ & $\begin{array}{l}19 \\
63 \%\end{array}$ & $\begin{array}{l}7 \\
24 \%\end{array}$ \\
\hline
\end{tabular}

(SA) - Strongly Agree, (A) - Agree, (D) - Disagree, (SD) - Strongly Disagree.

Responding to the Likert-scale statement in Table 8, Energy drinks have an effect on collegiate flight students' ability to pilot an aircraft, two-thirds of the student pilots agreed that energy drinks have an 
effect on flight students' ability to pilot an aircraft. The remaining 34\% disagreed that energy drinks affected flight students' ability to pilot an aircraft.

Almost 75\% of flight students disagreed with the statement: Energy drinks are an effective and safe method to increase a collegiate flight student's mental and physical performance, with one of the flight students stating on their survey; "I agree with the fact of energy drinks not affecting flying in a negative manner up to a point. I do believe that if you pound 3 energy drinks down within a short amount of time, there will be negative effects.” And yet, $90 \%$ of the respondents perceived it was okay for collegiate flight students to consume an energy drink the same day they piloted an aircraft.

Table 8. Collegiate Flight Students’ Perception of Energy Drinks Regarding Flight Students

\begin{tabular}{ll|l|l|l} 
Likert-Scale Statements & \multicolumn{1}{c|}{ SA } & A & D & SD \\
\hline \hline
\end{tabular}

(SA) - Strongly Agree, (A) - Agree, (D) - Disagree, (SD) - Strongly Disagree

\section{CONCLUSIONS}

College students have busy schedules and can be under a great amount of stress. One way students are combating this problem is by consuming energy drinks to get that much needed boost of energy. As a result, college students are relying on energy drinks more than ever. And it is no wonder. If college students are in need of a quick pick me up, they are drawn to names that promise vigor, like Full Throttle, Amp, or Rush (Better Medicine, 2011). As a result, college students are huge consumers and are highly targeted by these energy drink companies.

This research study sought to identify the existence of energy drink consumption among collegiate flight students at Oklahoma State University and their perceptions regarding the effects of energy drink consumption on their ability to pilot an aircraft. With a better understanding of collegiate flight students' perceptions of energy drink consumptions and their reasons for energy drink consumption; additional education programs can be implemented by aviation departments regarding the risks associated with energy drink consumption, as well as policies that discourage or even eliminate energy drink use among collegiate flight students - especially on those days that students pilot an aircraft.

Indicative of the data collected from this research study, the majority of participating collegiate flight students believed that energy drinks have an effect on their ability to pilot an aircraft. In addition, the majority of respondents indicated that heart palpitations, as well as jolt and crash episodes are common after consuming energy drinks. Furthermore, $56 \%$ of the flight students responded they only have to consume one energy drink to experience these mentioned side effects. And yet, profoundly, $90 \%$ of the flight students disagreed with the statement that collegiate flight students should not consume an energy drink the same day they pilot an aircraft. An interesting fact is that $70 \%$ of these flight students responding to the research survey have over 100 total flight hours; and twenty-seven percent of these 
students have accumulated 250 or more total flight hours; indicating that the majority of the participating students are upperclassmen and have been associated with the collegiate flight program for at least two to three academic years.

Even though research studies have linked energy drink consumption to risk-taking behaviors among college students, an overwhelming $87 \%$ of the flight students disagreed that energy drink consumption can be associated with risk-taking or behavior problems. In addition, it was about a 50/50 split among respondents that the chronic use of energy drinks can lead to other use of stimulants including Adderall and Ritalin; even though a 2010 study found that energy drink users were significantly more likely to initiate nonmedical use of prescription stimulants (Arria, et al, 2010).

Given that the energy drink market in the United States has increased by over 75\% in 2010, and the non-energy carbonated drink market has actually declined for the first time in 20 years, it is evident more and more people are consuming these beverages, which raises questions for college students who consume energy drinks (Pearson, 2010). Mostly, college students consume energy drinks in the afternoon; but now, a higher percentage of them are being consumed in the evenings with alcohol. A 2011 research study indicates that college students who have a high frequency of energy drink consumption (one energy drink per week) were at a significantly higher risk of alcohol dependence and episodes of heavy drinking (Arria et al., 2011).

With an increasing number of energy drink varieties introduced each year, the choices are virtually endless. Furthermore, the differences in caffeine and other stimulant levels among energy drink brands are as numerous. The consumer may assume that two similar-sized energy drinks would deliver the same amount of stimulant effect; however, one of the drinks can contain more than 300\% more caffeine than the other (Energyfiend.com, 2010). In addition to a huge variance in caffeine and other stimulant levels, energy drinks like Four Loco now contain high percentages of alcohol. These readily available energy drinks containing various levels of stimulants and alcohol can easily pose a significant threat to college students who consume them but are not familiar with the drink's contents, as they are not all created equal. This is especially concerning when energy drink consumption is prevalent within the collegiate flight environment.

Due to the increase in prominence of energy drink consumption on college campuses, the various levels of energy drink ingredients, their physical and cognitive effects on students, and the established perception of collegiate flight respondents from this study; the collegiate aviation community should be aware and cautious of the negative effects of energy drink consumption in the collegiate flight environment.

Even though there were a few limitations associated with this study: (1) the number of participants during the data collection phase of this project was relatively small; therefore, the generalization of findings may be somewhat limited, (2) homogeneity, this study only included collegiate flight students at one university; if flight students from other collegiate flight programs also completed the research instrument, the results might be different, and (3) the participants' inability to be $100 \%$ reliable in their survey responses - the results provide a foundation for future research regarding collegiate flight students' responses and perceptions of energy drink consumption and the potential effects that consuming energy drinks may have on piloting aircraft.

Future research should be done by collegiate aviation to examine the consumption of energy drinks by collegiate flight students. First of all, a much larger student population (national study) needs to be researched to fully understand the effects that energy drink consumption has on collegiate flight students; as well as their consumption characteristics (when, why, and how often). Furthermore, additional simulated flight studies should be performed to determine additional effects that energy drink 
consumption may have on the cockpit performance of collegiate flight students; in an effort to minimize the daily risks associated with collegiate flight students piloting an aircraft. Lastly, the perceptions of collegiate flight program administrators should be researched to better understand their knowledge and thoughts regarding the consumption of energy drinks by their own flight students.

In short, careful and continued consideration should be given to energy drink consumption on college campuses and the perception of collegiate flight students regarding the consumption of energy drinks. Hopefully the ultimate lesson to be learned by students is that when it comes to obtaining energy, look elsewhere than an energy drink. Sure, college students can temporarily increase their energy level with energy drinks, but as documented and researched, they are bound to crash. 


\section{REFERENCES}

American Heart Association (2007, November). Energy drinks may pose risks for people with high blood pressure, heart disease. ScienceDaily. Retrieved from http://www.sciencedaily.com/releases/2007/11/071106092009.htm

Arria, A.M., Caldeira, K.M., Kasperski, S.J., Vincent, K.B., Griffiths, R.R., \& O’Grady, K.E. (2011, February). Energy drink consumption and increased risk for alcohol dependence [Electronic Version]. Alcoholism: Clinical \&Experimental Research, 35(2), 365-375.

Arria, A.M., Caldeira, K.M., Kasperski, S.J., O’Grady, K.E., Vincent, K.B., Griffiths, R.R., \& Wish, E.D. (2010). Increased alcohol consumption, nonmedical prescription drug use, and illicit drug use are associated with energy drink consumption among college students. Journal of Addiction Medicine, $4(2), 74-80$.

Better Medicine.com (2011). Vitamins, herbs, and supplements: Do the "energy boosters" work? Retrieved from http://www.bettermedicine.com/topic/sleep-disorders/boosting-your-energy?p=12

Buchanan, M. (2010). Addiction to energy drinks. Retrieved from http://www.helium.com/items/845026addiction-to-energy-drinks

Depperschmidt, C.L., Bliss, T.J., \& Woolsey, C.L. (2010, Fall). The effect of energy drink consumption on collegiate flight students' pilot skills in a simulated flight environment. Collegiate Aviation Review, 28(2), 1-15.

Energyfiend.com (2010). Caffeine Content of Drinks. Retrieved from http://www.energyfiend.com/thecaffeine-database/

Gay, L.R., Mills, G.E., \& Airasian, P. (2006). Educational Research: Competencies for Analysis and Applications ( $8^{\text {th }}$ Ed.). Upper Saddle River, New Jersey: Pearson Prentice Hall.

George, D., \& Mallery, P. (2003). SPSS for Windows step by step: A simple guide and reference. 11.0 update $\left(4^{\text {th }}\right.$ ed.). Boston: Allyn \& Bacon.

Helm, B. (2005, January). Energy drinks build their buzz. Bloomberg Businessweek. Retrieved from http://www.businessweek.com/smallbiz/content/jan2005/sb2005015_8196_sb017.htm

Keegan, M.C. (2010, October). Ramapo College bans energy drinks. SayCampusLife. Retrieved from http://www.saycampuslife.com/2010/10/18/ramapo-college-bans-energy-drinks/

Malinauskas, B. M., Aeby, V. G., Overton, R. F., Carpenter-Aeby, T., \& Barber-Heidal, K. (2007). A survey of energy drink consumption patterns among college students. Nutrition Journal, 6, 35. doi:10.1186/1475-2891-6-35

Melnick, M. (2010, November). Will the FDA ban sales of Four Loco? Time Healthland. Retrieved from http://healthland.time.com/2010/11/16/will-the-fda-ban-sales-of-four-loko/

Miller, W. R., \& Carroll, K. M. (2006). Rethinking substance abuse: What the science shows, and what we should do about it. New York: Guilford Press. 
Oteri, A., Salvo, F., Caputi, A., \& Calapai, G. (2007). Intake of energy drinks in association with alcoholic beverages in a cohort of students of the school of medicine of the University of Messina. Alcoholism: Clinical and Experimental Research, 31(10), 1677-1681.

Park, A. (2011, February). Energy drinks may harm health, especially for children. TIME Healthland. Retrieved from http://healthland.time.com/2011/02/14/energy-drinks-may-harm-health/

Pearson, D. (2010, February). The growing popularity of energy drinks. Article Alley. Retrieved from http://www.articlealley.com/article_1374325_17.html

Pohler, H. (2010, January). Caffeine intoxication and addiction. The Journal for Nurse Practitioners, 6 (1), 49-52.

University at Buffalo (2008, July). Energy drinks linked to risk-taking behaviors among college students. ScienceDaily. Retrieved from http://www.sciencedaily.com-/releases/2008/07/080724150438.htm 